\title{
Cryptosporidium ubiquitum, C. muris and Cryptosporidium deer genotype in wild cervids and caprines in the Czech Republic
}

\author{
Michaela Kotková ${ }^{1,2}$, Karel Němejc ${ }^{2,3}$, Bohumil Sak ${ }^{1}$, Vladimír Hanzal ${ }^{2,4}$, Dana Květoňová1 , Lenka Hlásková ${ }^{1}$, \\ Šárka Čondlová ${ }^{1,2}$, John McEvoy ${ }^{5}$ and Martin Kváćc ${ }^{1,2}$
}

\author{
${ }^{1}$ Institute of Parasitology, Biology Centre of the Czech Academy of Sciences, České Budějovice, České Budějovice, Czech Republic; \\ ${ }^{2}$ Faculty of Agriculture, University of South Bohemia, České Budějovice, Czech Republic; \\ ${ }^{3}$ Institute of Education and Communication, Czech University of Life Sciences, Praha, Czech Republic; \\ ${ }^{4}$ Faculty of Forestry and Wood Sciences, Czech University of Life Sciences, Praha, Czech Republic; \\ ${ }^{5}$ Department of Veterinary and Microbiological Sciences, North Dakota State University, Fargo, ND, USA
}

\begin{abstract}
A total of 269 faecal samples of various game animals, including 136 red deer (Cervus elaphus Linnaeus), 64 European fallow deer (Dama dama [Linnaeus]), 26 white-tailed deer (Odocoileus virginianus [Zimmermann]), and 43 mouflon sheep (Ovis orientalis musimon Pallas) were collected at 15 game preserves across the Czech Republic and examined for infection with species of Cryptosporidium Tyzzer, 1910 using microscopy (following aniline-carbol-methyl violet staining) and molecular tools. Oocysts of Cryptosporidium spp. were detected in one faecal sample originating from red deer. Ten positive cases of infection with cryptosporidia, including the case that was positive by microscopy, were detected using nested PCR. No associations between infection with cryptosporidia and diarrhoea were detected. Phylogenetic analyses based on the small subunit of the rRNA gene revealed the presence of three Cryptosporidium species/genotypes in ten positive samples: Cryptosporidium ubiquitum Fayer, Santín et Macarisin, 2010 was identified in five red deer, C. muris Tyzzer, 1907 in three samples (from a red deer, white-tailed deer and mouflon sheep), and Cryptosporidium deer genotype in two white-tailed deer. Subtyping of isolates of C. ubiquitum based on sequence analysis of the 60-kDa glycoprotein gene revealed that they belong to the XIId family. Finding C. muris and C. ubiquitum XIId for the first time in various wild cervids and caprines broadens their host range.
\end{abstract}

Keywords: Cryptosporidiidae, epidemiology, phylogeny, SSU, gp60

The genus Cryptosporidium Tyzzer, 1910 is composed of protistan parasites that infect epithelial cells in the microvillus border of the gastrointestinal tract of all classes of vertebrates (Ryan and Xiao 2014). Currently, as many as 30 valid species of Cryptosporidium have been described from fish, amphibians, reptiles, birds and mammals using morphological, biological and molecular data. In addition to these species recognised as valid, more than 100 genotypes have been described from various vertebrate hosts and environmental sources that lack sufficient morphological and biological data for description as separate species (Kváč et al. 2014, Ryan and Xiao 2014).

The disease caused by these apicomplexans, cryptosporidiosis, manifests as a self-limiting, chronic or persistent diarrhoea, often without clinical signs. Even though C. parvum Tyzzer, 1912 and C. hominis Morgan-Ryan, Fall, Ward, Hijjawi, Sulaiman, Fayer, Thompson, Olson, Lal et Xiao, 2002 cause most cases of human cryptosporid- iosis worldwide (Morgan-Ryan et al. 2002), more than 20 species/genotypes of Cryptosporidium are infectious for humans and about two thirds of these originate from wild, free-ranging animals (Ortega and Kváč 2013). Game animals belonging to the family Cervidae (cervids) and the subfamily Caprinae (caprines) of the family Bovidae may therefore be important reservoir hosts for cryptosporidia (Kváč et al. 2014).

Cryptosporidiosis in cervids was first described in New Zealand in 1985 (Orr et al. 1985) and occurs worldwide (Kváč et al. 2014, Robertson et al. 2014), but information is lacking on the species/genotypes of Cryptosporidium infecting these animals. Only half of the more than 20 studies used the molecular tools necessary to identify the species/ genotype (Kváč et al. 2014, Santín and Fayer 2014).

The studies using molecular analyses revealed the presence of eight species/genotypes of Cryptosporidium: C. parvum, C. ubiquitum Fayer, Santín et Macarisin, 
Table 1. The distribution of Cryptosporidium spp. among examined wild red deer (Cervus elaphus Linnaeus), European fallow deer (Dama dama [Linnaeus]), white-tailed deer (Odocoileus virginianus [Zimmermann]) and mouflon sheep (Ovis orientalis musimon Pallas) in the Czech Republic based on microscopical examination and molecular characterisation at SSU and gp60 loci.

\begin{tabular}{|c|c|c|c|c|c|c|c|c|c|}
\hline \multirow{3}{*}{ Host } & \multirow{3}{*}{ Locality } & \multirow{3}{*}{ Area (ha) } & \multirow{3}{*}{$\begin{array}{c}\text { No. of } \\
\text { screened } \\
\text { samples }\end{array}$} & \multirow{3}{*}{$\begin{array}{c}\text { Microscopy } \\
\text { positive }\end{array}$} & \multirow{3}{*}{$\begin{array}{l}\text { PCR pos- } \\
\text { itive }\end{array}$} & \multicolumn{4}{|c|}{ Molecular characterisation of Cryptosporidium spp. } \\
\hline & & & & & & \multicolumn{2}{|c|}{ C. ubiquitum } & \multirow{2}{*}{$\begin{array}{c}\text { deer genotype } \\
\text { (SSU) }\end{array}$} & \multirow{2}{*}{$\begin{array}{l}\text { C. muris } \\
\text { (SSU) }\end{array}$} \\
\hline & & & & & & (SSU) & $(g p 60)$ & & \\
\hline \multirow{12}{*}{ Red deer } & 1 & 70 & 11 & - & - & - & - & - & - \\
\hline & 2 & 60 & 11 & - & - & - & - & - & - \\
\hline & 3 & 63 & 30 & - & - & - & - & - & - \\
\hline & 4 & 30 & 10 & - & 1 & 1 & 1 & - & - \\
\hline & 5 & 50 & 11 & - & - & - & - & - & - \\
\hline & 6 & 60 & 10 & - & - & - & - & - & - \\
\hline & 7 & 160 & 11 & - & - & - & - & - & - \\
\hline & 8 & 77 & 9 & - & - & - & - & - & - \\
\hline & 9 & 255 & 11 & 1 & 5 & 4 & 4 & - & 1 \\
\hline & 10 & 16 & 10 & - & - & - & - & - & - \\
\hline & 11 & 28 & 12 & - & - & - & - & - & - \\
\hline & Subtotal & & 136 & 1 & 6 & 5 & 5 & - & 1 \\
\hline \multirow{4}{*}{ European fallow deer } & 13 & 652 & 30 & - & - & - & - & - & - \\
\hline & 14 & 30 & 29 & - & - & - & - & - & - \\
\hline & 6 & 60 & 5 & - & - & - & - & - & - \\
\hline & Subtotal & & 64 & - & - & - & - & - & - \\
\hline \multirow{2}{*}{ White-tailed deer } & 12 & 35 & 26 & - & 3 & - & - & 2 & 1 \\
\hline & Subtotal & & 26 & - & 3 & - & - & 2 & 1 \\
\hline \multirow{4}{*}{ Mouflon sheep } & 3 & 63 & 31 & - & 1 & - & - & - & 1 \\
\hline & 15 & 190 & 5 & - & - & - & - & - & - \\
\hline & 6 & 60 & 7 & - & - & - & - & - & - \\
\hline & Subtotal & & 43 & - & 1 & - & - & - & 1 \\
\hline Total & & & 269 & 1 & 10 & 5 & 5 & 2 & 3 \\
\hline
\end{tabular}

2010, C. bovis Fayer, Santín et Xiao, 2005, C. ryanae Fayer, Santín et Trout, 2008, Cryptosporidium hominis-like, Cryptosporidium deer genotype, Cryptosporidium muskrat genotype II and Cryptosporidium caribou genotype (Kváč et al. 2014, Wells et al. 2015). Even less is known about epidemiology of cryptosporidia infecting caprines. Whereas cryptosporidia of domestic sheep and goats have been intensively studied (Robertson 2009), only seven studies have focused on cryptosporidia of free-ranging caprines, two of which were from mouflon sheep (Gómez et al. 2000, Ryan et al. 2003). Two studies have identified C. ubiquitum (previously known as Cryptosporidium cervine genotype, cervid, W4 or genotype 3) and C. tyzzeri Ren, Zhao, Zhang, Ning, Jian, Wang, Lv, Wang, Arrowood et Xiao, 2012 (previously known as Cryptosporidium mouse genotype) in free-ranging caprids (Ryan et al. 2003, Karanis et al. 2007).

Thus the present study aimed to investigate the distribution of species/genotypes of Cryptosporidium in free-ranging cervids and caprines in the Czech Republic by sequence analysis of the small subunit ribosomal RNA gene, and to assess the distribution and diversity of potentially zoonotic subtypes by sequence analysis of a gene encoding a 60-kDa glycoprotein.

\section{MATERIALS AND METHODS}

The research was performed in 15 randomly selected game preserves with areas ranging from 16 to 652 ha in the Czech Re- public. A total of 269 faecal samples from red deer (Cervus elaphus Linnaeus), European fallow deer (Dama dama [Linnaeus]), white-tailed deer (Odocoileus virginianus [Zimmermann]), and mouflon sheep (Ovis orientalis musimon Pallas) were collected individually (Table 1). Fresh faecal samples were taken directly from the ground immediately after defecation at feeding places in forests. Each sample was placed into an individual sterile plastic container without fixative, transported to the laboratory in a cool box and stored at $4{ }^{\circ} \mathrm{C}$ until processing. The faecal consistency (loose if it took the form of the container and solid if it maintained its original shape) was noted at the time of sampling. All samples were microscopically analysed within $24 \mathrm{~h}$ using the aniline-carbol-methyl violet staining method (Miláček and Vítovec 1985). Infection of intensity was expressed as the number of oocysts per gram of faeces as previously described (Kváč et al. 2007).

To detect and identify species of Cryptosporidium, DNA from faecal samples was extracted as previously reported (Sak et al. 2008) and nested-PCR protocols were used to amplify partial sequences of the Cryptosporidium small-subunit (SSU) rRNA gene according to Jiang et al. (2005) and the Cryptosporidium 60-kDa glycoprotein gene (gp60) according to Li et al. (2014). Amplicons of secondary PCR products were sequenced directly in both directions with an ABI 3130 Genetic Analyzer (Applied Biosystems, Foster City, CA). The sequences were assembled using ChromasPro 1.32 (www.technelysium.com.au/ChromasPro. html), edited using BioEdit 7.04 (www.mbio.ncsu.edu/BioEdit/ bioedit.html) and aligned using MAFFT version 7 online server (http://mafft.cbrc.jp/alignment/software/). 


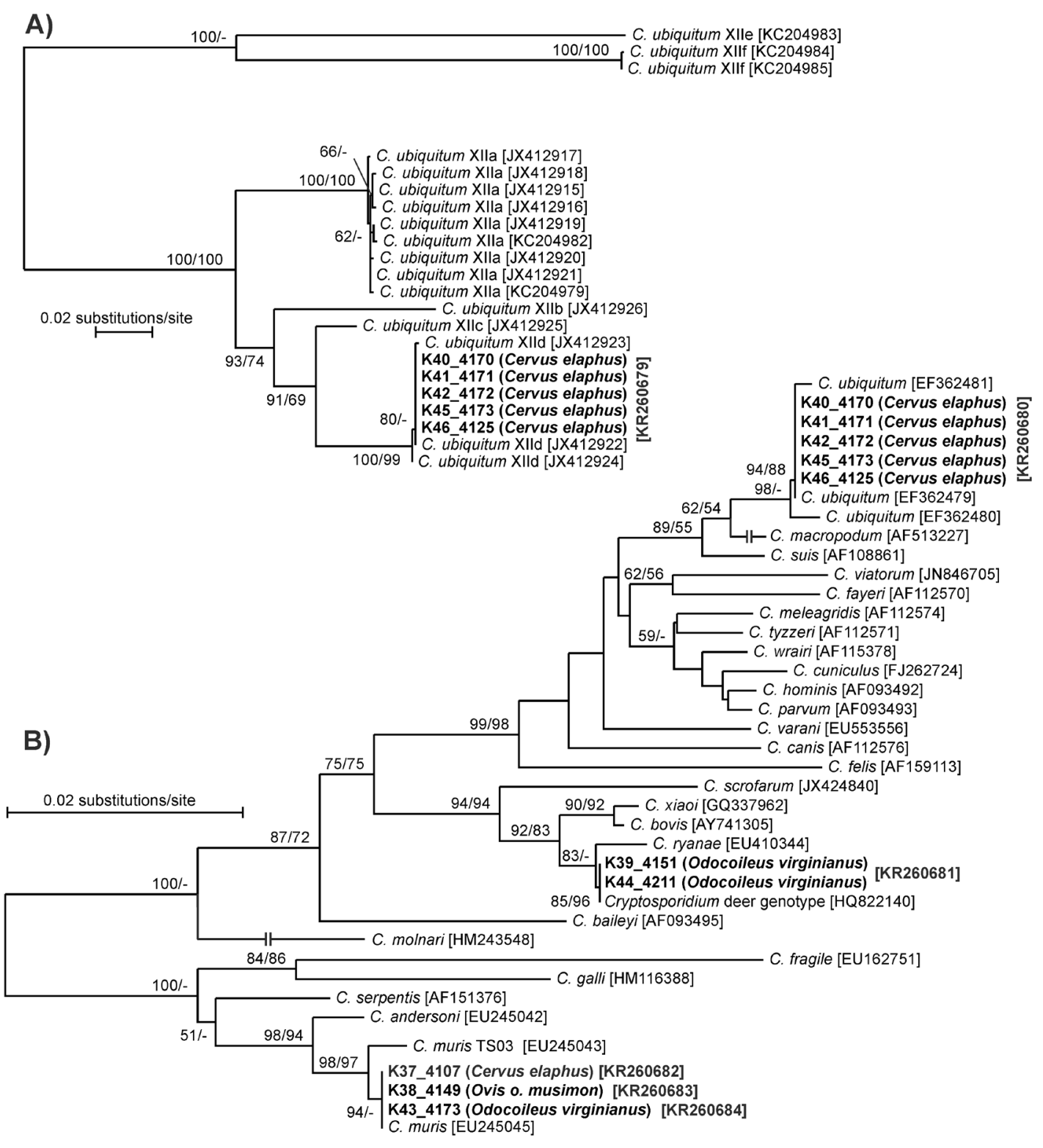

Fig 1. Phylogenetic relationships between isolates of Cryptosporidium spp. in this study (highlighted by bold) and other Cryptosporidium spp. by a neighbour-joining analysis/maximum likelihood (ML) of (A) the partial gp60 gene (1 015 base positions in the final dataset; ML $\operatorname{LogL}=-3161.49$ ) and (B) the SSU rRNA gene ( 717 base positions in the final dataset; ML $\operatorname{LogL}=-257.98$ ). The percentage of replicate trees in which the associated taxa clustered together in the bootstrap test (1000 replicates). Numbers at the nodes represent bootstrap values for the nodes gaining more than $50 \%$ support. Interrupted branches have been shortened five-fold.

Phylogenetic relationships were inferred using the neighbour-joining and maximum likelihood methods. The substitution model that best fits the alignment was selected using the Bayesian information criterion. The General Time Reversible model was selected for alignment of SSU and the Kimura 2-parameter test was selected for the gp 60 alignment. Both models were used under an assumption that rate variation among sites was gamma distributed. A bootstrap consensus tree was inferred from 1000 pseudoreplicates. Phylogenetic analyses, including analysis of substitution model goodness of fit, were carried out using MEGA 6.06. (www.megasoftware.net/). Phylogenetic trees were edited for style using CorelDrawX7 (Corel Corporation, Ottawa, Ontario, Canada). Sequences have been deposited in GenBank under the accession numbers KR260679-KR260684.

\section{RESULTS}

A total of 269 faecal samples of red deer $(n=136)$, European fallow deer $(n=64)$, white-tailed deer $(n=26)$, and mouflon sheep $(n=43)$ from 15 localities within the Czech Republic were examined by microscopy and molecular tools (Table 1). Using a PCR assay to amplify a fragment of the SSU rRNA gene, cryptosporidia were detected in 10 faecal samples (3.7\%) (Table 1). Direct sequencing of SSU PCR-amplified products revealed the presence of Cryptosporidium ubiquitum in five red deer originating from two different game preserves, Cryptosporidium deer genotype in two white-tailed deer, and C. muris Tyzzer, 1907 in a red deer, a white-tailed deer and a mouflon sheep (Table 1). Cryptosporidium was not detected in European 
fallow deer. Cryptosporidium muris isolates shared 100\% sequence identity with C. muris RN66 (EU245045), and C. ubiquitum isolates shared $100 \%$ identity with C. ubiquitum (EF362479), which was previously known as Cryptosporidium cervine genotype 1 (Table 1, Fig. 1). Only one sample, originating from a red deer and positive for C. ubiquitum by sequence analysis, was positive by microscopy, with an infection intensity of $\sim 4000$ oocysts per gram. The gp60 gene was amplified and sequenced from all five $C$. ubiquitum positive samples. Sequences were identical to that from $C$. ubiquitum subtype family XIId (JX412922) (Fig. 1). No mixed infections of Cryptosporidium spp. or diarrhea were observed in the examined faecal samples.

\section{DISCUSSION}

In the present study, the overall prevalence of cryptosporidia in cervids (red deer, European fallow deer and white-tailed deer) and caprines (mouflon sheep) was low (3.7\%). Cryptosporidium spp. were most frequently detected in white-tailed deer $(12 \% ; 3 / 26)$, which is consistent with earlier reports of prevalence in the range $1-11 \%$ (Rickard et al. 1999, Perz and Le Blancq 2001, Heitman et al. 2002, Santín and Fayer 2014)

Overall the prevalence in deer and mouflon sheep kept in game preserves (4\%) was significantly lower than that in farmed red and roe deer (Capreolus capreolus [Linnaeus]) in Ireland and in Scotland, where up to $60 \%$ and $80 \%$ of animals were positive for Cryptosporidium, respectively (Skerrett and Holland 2001, Wells et al. 2015). A similarly high prevalence (25-100\%) was observed in fallow and red deer kept in zoological gardens (Heuschele et al. 1986). The low prevalence in the present study could be explained by the low population density, whose increase could lead to higher infection rates due to environmental burden (Wells et al. 2015). Generally, population density of farmed deer reaches $1-15$ animals per ha, whereas in game preserves it is only 1-2 per ha. In contrast, Paziewska et al. (2007) reported lower prevalence of farmed red deer (5\%) compared to wild red deer (27\%) in Poland.

The difference between these studies could also be explained by the presence of different Cryptosporidium species. Whereas C. parvum, one of the most virulent species of Cryptosporidium, was detected as a causative agent in more than $80 \%$ of cases in a study by Wells et al. (2015), no infection by this species was observed in the present study. Due to the low number of studies and absence of genotyping of Cryptosporidium in other studies, it is not possible to draw any conclusions.

Phylogenetic analyses revealed the presence of three species/genotypes of Cryptosporidium. Whereas C. ubiquitum and Cryptosporidium deer genotype were previously identified in various cervids and caprines (Perz and Le Blancq 2001, Xiao et al. 2002, Feng et al. 2007), C. muris has not been confirmed in cervids until now. However, a C. muris-like organism was detected by immunofluorescence assay in black-tailed deer (Odocoileus hemionus columbianus [Richardson]) by Deng and Cliver (1999). Although $C$. muris is typically a parasite of mice and rats, it has been reported from many hoofed animals, including the Bactrian camel (Camelus bactrianus Linnaeus), Cuvier's gazelle (Gazella cuvieri [Ogilby]), domestic sheep (Ovis orientalis aries Linnaeus), domestic goat (Capra aegagrus hircus Linnaeus), mountain goat (Oreamnos americanus [de Blainville]) and reticulated giraffe (Giraffa camelopardalis reticulata de Winton) (Pospischil et al. 1987, Fayer et al. 1991, Rhee et al. 1998, Valigurová et al. 2007, Kodádková et al. 2010). However, the susceptibility of deer to C. muris is unclear. Deer may be a mechanical vector for C. muris ingested with contaminated food, similarly to pigs and some reptiles (Kváč et al. 2012). In particular, supplementary feed given to deer and mouflons could be susceptible to contamination by rodent faeces during storage.

Cryptosporidium deer genotype, which is closely related to C. ryanae, has been reported in white-tailed deer in the USA (Xiao et al. 2002, Santín and Fayer 2014), and roe deer and red deer in the UK (Robinson et al. 2011, Wells et al. 2015). Cryptosporidium deer genotype was detected only in white-tailed deer in this study. In contrast to the study performed by Santín and Fayer (2014), where Cryptosporidium deer genotype was the only detected species/ genotype of Cryptosporidium in deer, most other studies of deer, including the present study, have found the deer genotype to be in the minority (Robinson et al. 2011, Wells et al. 2015). Although this genotype is host-specific, its prevalence within the deer population appears to be low.

Unlike C. muris and Cryptosporidium deer genotype, C. ubiquitum has a broad host range. It has been detected frequently in rodents, carnivores, primates, and domestic and wild artiodactyls, including swamp deer (Cervus duvauceli Cuvier) from Nepal, roe deer from England, red deer from the Czech Republic and sika deer (Cervus nippon Temminck) from China (Hajdušek et al. 2004, Wang et al. 2008, Fayer et al. 2010, Feng et al. 2012). Li et al. (2014) suggested that $C$. ubiquitum gp60 subtype families had different host specificity: XIIa was found in ruminants worldwide, XIIb-XIId were found in rodents in the United States, and XIIe and XIIf were found in rodents in the Slovak Republic. Our isolates originating from 5 red deer were identical to XIId family isolated from raccoon, squirrel, beaver, chipmunk, and woodcock in USA (Li et al. 2014), expanding the host range and questioning the restricted host specificity of the XIId family.

In contrast to the clear association of infection with cryptosporidia with clinical disease in farmed cervids and caprines reported worldwide (Robertson et al. 2014), we did not find any clinical manifestation of cryptosporidial infection in the present study. This difference may be due either to the effect of age (we studied adults, whereas diarrhoea was mostly reported in deer calves) or the absence of $C$. parvum in present study, because this species is considered to be the most likely cause of cryptosporidiosis in calves of deer (Robertson et al. 2014). Consistent with the absence of clinical effects and similar to the findings of Skerrett and Holland (2001), we observed a low oocyst excretion in infected animals.

Of the species/genotypes of Cryptosporidium identified in the wild cervids and caprines in the present study, two 
(C. ubiquitum and C. muris) have been associated with human cryptosporidiosis (Ortega and Kváč 2013). In the case of $C$. muris, which has been found rarely in humans, the health risk can be considered low. However, C. ubiquitum is commonly found in humans (Fayer et al. 2010, Elwin et al. 2012) and subtype family XIId has caused human cryptosporidiosis ( $\mathrm{Li}$ et al. 2014). Therefore, wild cervids could represent a potential, although in our view limited, source of Cryptosporidium infection in humans.
Acknowledgements. This study was funded by the Czech Science Foundation (project No. 15-01090S), a project of the Grant Agency of the University of South Bohemia (project No. 011/2013/Z) and National Institutes of Health (NIH), USA (project No. 2P20 RR015566). The authors thank all rangers involved in the project for providing data and biological material for our research.

\section{REFERENCES}

Deng M.Q., Cliver D.O. 1999: Improved immunofluorescence assay for detection of Giardia and Cryptosporidium from asymptomatic adult cervine animals. Parasitol. Res. 85: 733-736.

Elwin K., Hadfield S.J., Robinson G., Chalmers R.M. 2012: The epidemiology of sporadic human infections with unusual cryptosporidia detected during routine typing in England and Wales, 2000-2008. Epidemiol. Infect. 140: 673-683.

Fayer R., Phillips L., Anderson B.C., Bush M. 1991: Chronic cryptosporidiosis in a Bactrian camel (Camelus bactrianus). J. Zoo. Wildlife. Med. 22: 228-232.

FAyer R., SAntín M., Macarisin D. 2010: Cryptosporidium ubiquitum n. sp. in animals and humans. Vet. Parasitol. 172: 23-32.

Feng Y., Alderisio K.A., Yang W., Blancero L.A., Kuhne W.G., Nadareski C.A., Reid M., Xiao L. 2007: Cryptosporidium genotypes in wildlife from a New York watershed. Appl. Environ. Microbiol. 73: 6475-6483.

Feng Y., Karna S.R., Dearen T.K., Singh D.K., Adhikari L.N., Shrestha A., Xiao L. 2012: Common occurrence of a unique Cryptosporidium ryanae variant in zebu cattle and water buffaloes in the buffer zone of the Chitwan National Park, Nepal. Vet. Parasitol. 185: 309-314.

Gómez M.S., Torres J., Gracenea M., Fernandez-Morán J., Gonzalez-Moreno O. 2000: Further report on Cryptosporidium in Barcelona zoo mammals. Parasitol. Res. 86: 318-323.

Hajdušek O., Ditrich O., Šlapeta J. 2004: Molecular identification of Cryptosporidium spp. in animal and human hosts from the Czech Republic. Vet. Parasitol. 122: 183-192.

Heitman T.L., Frederick L.M., Viste J.R., Guselle N.J., Morgan U.M., Thompson R.C., Olson M.E. 2002: Prevalence of Giardia and Cryptosporidium and characterization of Cryptosporidium spp. isolated from wildlife, human, and agricultural sources in the North Saskatchewan River Basin in Alberta, Canada. Can. J. Microbiol. 48: 530-541.

Heuschele W.P., Oosterhuis J., Janssen D., Robinson P.T. Ensley P.K., Meier J.E., Olson T., Anderson M.P., BeNIRSCHKE K. 1986: Cryptosporidial infections in captive wild animals. J. Wildl. Dis. 22: 493-496.

JiAng J., Alderisio K.A., XIAO L. 2005: Distribution of Cryptosporidium genotypes in storm event water samples from three watersheds in New York. Appl. Environ. Microbiol. 71: 44464454

Karanis P., Plutzer J., Halim N.A., Igori K., Nagasawa H., ONGERTH J., LiQING M. 2007: Molecular characterization of Cryptosporidium from animal sources in Qinghai province of China. Parasitol. Res. 101: 1575-1580.

Kodádková A., Kváč M., Ditrich O., Sak B., Xiao L. 2010 : Cryptosporidium muris in a reticulated giraffe (Giraffa camelopardalis reticulata). J. Parasitol. 96: 211-212.

Kváč M., Kestřánová M., KvĚtoňová D., Kotková M., ORTEGA Y., McEvoy J., SAK B. 2012: Cryptosporidium tyzzeri and Cryptosporidium muris originated from wild West-European house mice (Mus musculus domesticus) and East-European house mice (Mus musculus musculus) are non-infectious for pigs. Exp. Parasitol. 131: 107-110.
Kváč M., McEvoy J., Stenger B., Clark M. 2014: Cryptosporidiosis in other vertebrates. In: S.M. Cacciò and G. Widmer (Eds.), Cryptosporidium: Parasite and Disease. Springer, Wien, pp. 237-326.

Kváč M., Ondráčková Z., Květoňová D., SAK B., Vítovec J. 2007: Infectivity and pathogenicity of Cryptosporidium andersoni to a novel host, southern multimammate mouse (Mastomys coucha). Vet. Parasitol. 143: 229-233.

Li N., Xiao L., Alderisio K., Elwin K., Cebelinski E., Chalmers R., Santin M., Fayer R., Kváč M., Ryan U., Sak B., Stanko M., Guo Y., Wang L., Zhang L., Cai J., Roellig D., FENG Y. 2014: Subtyping Cryptosporidium ubiquitum, a zoonotic pathogen emerging in humans. Emerg. Infect. Dis. 20: 217-224.

MiláčeK P., Vítovec J. 1985: Differential staining of cryptosporidia by aniline-carbol-methyl violet and tartrazine in smears from feces and scrapings of intestinal mucosa. Folia Parasitol 32: 50 .

Morgan-Ryan U.M., Fall A., Ward L.A., Hijuawi N., SuLaiman I., Fayer R., Thompson R.C., Olson M., Lal A., XIAO L. 2002: Cryptosporidium hominis n. sp. (Apicomplexa: Cryptosporidiidae) from Homo sapiens. J. Eukaryot. Microbiol. 49: 433-440.

Orr M.B., Mackintosh C.G., Suttie J.M. 1985: Cryptosporidiosis in deer calves. New Zeal. Vet. J. 33: 151-152.

Ortega Y.R., Kváč M. 2013: Foodborne protozoa. In: R.G. Labbé and S. García (Eds.), Guide to Foodborne Pathogens. John Wiley \& Sons, Oxford, pp. 303-316.

Paziewska A., Bednarska M., Nieweglowski H., KarbowiAK G., BAJER A. 2007: Distribution of Cryptosporidium and Giardia spp. in selected species of protected and game mammals from north-eastern Poland. Ann. Agric. Environ. Med. 14: 265-270.

Perz J.F., Le BlancQ S.M. 2001: Cryptosporidium parvum infection involving novel genotypes in wildlife from lower New York State. Appl. Environ. Microbiol. 67: 1154-1162.

Pospischil A., Stiglmair-Herb M.T., von Hegel G., Wiesner H. 1987: Abomasal cryptosporidiosis in mountain gazelles. Vet. Rec. 121: 379-380.

Rhee J.K., Kim H.C., Eun G.S. 1998: Infection kinetics and developmental biology of Cryptosporidium muris (strain MCR) in Korean native kids and Corriedale lambs. Kor. J. Parasitol. 36: 171-181.

Rickard L.G., Siefker C., Boyle C.R., Gentz E.J. 1999: The prevalence of Cryptosporidium and Giardia spp. in fecal samples from free-ranging white-tailed deer (Odocoileus virginianus) in the southeastern United States. J. Vet. Diagn. Invest. 11: $65-72$

Robertson L.J. 2009: Giardia and Cryptosporidium infections in sheep and goats: a review of the potential for transmission to humans via environmental contamination. Epidemiol. Infect. 137: 913-921.

Robertson L.J., Buörkman C., Axén C., Fayer R. 2014: Cryptosporidiosis in farmed animals. In: S.M. Cacciò and G. Widmer (Eds.), Cryptosporidium: Parasite and Disease. Springer, Wien, pp. $149-236$ 
Robinson G., Chalmers R.M., Stapleton C., Palmer S.R., Watkins J., Francis C., Kay D. 2011: A whole water catchment approach to investigating the origin and distribution of Cryptosporidium species. J. Appl. Microbiol. 111: 717-730.

Ryan U., Xiao L. 2014: Taxonomy and molecular taxonomy. In: S.M. Cacciò and G. Widmer (Eds.), Cryptosporidium: Parasite and Disease. Springer, Wien, pp. 3-42.

Ryan U., Xiao L., Read C., Zhou L., Lal A.A., Pavlásek I. 2003: Identification of novel Cryptosporidium genotypes from the Czech Republic. Appl. Environ. Microbiol. 69: 4302-4307.

SaK B., Kvíč M., Hanzlíková D., Cama V. 2008: First report of Enterocytozoon bieneusi infection on a pig farm in the Czech Republic. Vet. Parasitol. 153: 220-224.

SANTÍN M., FAYER R. 2014: Enterocytozoon bieneusi, Giardia and Cryptosporidium infecting white-tailed deer. J. Eukaryot. Microbiol. 62: 34-43.

Sker rett H.E., Holland C.V. 2001: Asymptomatic shedding of Cryptosporidium oocysts by red deer hinds and calves. Vet. Parasitol. 94: 239-246.
Valigurová A., Hofmannová L., Koudela B., Vávra J. 2007: An ultrastructural comparison of the attachment sites between Gregarina steini and Cryptosporidium muris. J. Eukaryot. Microbiol. 54: 495-510.

Wang R., Wang J., Sun M., Dang H., Feng Y., Ning C., Jian F., Zhang L., XIAO L. 2008: Molecular characterization of the Cryptosporidium cervine genotype from a sika deer (Cervus nippon Temminck) in Zhengzhou, China and literature review. Parasitol. Res. 103: 865-869.

Wells B., Shaw H., Hotchkiss E., Gilray J., Ayton R., Green J., Katzer F., Wells A., Innes E. 2015: Prevalence, species identification and genotyping Cryptosporidium from livestock and deer in a catchment in the Cairngorms with a history of a contaminated public water supply. Parasit. Vectors 8: 66.

Xiao L., Sulaiman I.M., Ryan U.M., Zhou L., Atwill E.R., Tischler M.L., Zhang X., Fayer R., Lal A.A. 2002: Host adaptation and host-parasite co-evolution in Cryptosporidium: implications for taxonomy and public health. Int. J. Parasitol. 32: $1773-1785$.

Cite this article as: Kotková M., Němejc K., Sak B., Hanzal V., Květoňová D., Hlásková L., Čondlová Š., McEvoy J., Kváč M. 2016: Cryptosporidium ubiquitum, C. muris and Cryptosporidium deer genotype in wild cervids and caprines in the Czech Republic. Folia Parasitol. 63: 003. 